\title{
Effect of cold plasma on black beans (Phaseolus vulgaris $L$.), fungi inactivation and micro-structures stability
}

\author{
Cristina Link Rüntzel1*, Juliana Regina da Silva1, Bruna Aparecida da Silva', Elisa Siegel Moecke², \\ Vildes Maria Scussel ${ }^{1}$
}

${ }^{1}$ Mycotoxicology and Food Contaminants laboratory - LABMICO, Food Science and Technology department, Agricultural Sciences Center, Santa Catarina Federal University, ${ }^{2}$ Environmental and Sanitary Engineering department, Southern Santa Catarina University - UNISUL, Av. Pedra Branca, 25, Palhoça, SC, Brasil

\section{A B S T R A C T}

The Cold Plasma (CP) treatment efficiency to inactivate naturally fungi contaminated beans (Phaseolus vulgaris L.), Class black, and the effects in micro-structures stability were investigated. Kernels were exposed to CP ( 8 kv intensity and $510 \mathrm{~W}$ power) at different times $(5,10,20$ and $30 \mathrm{~min})$ followed by incubation to verify the antifungal effect and their micro-structural resistance through microscopy (stereo -SM and scanning electron - SEM) observation. The treatment was effective to fungal inactivation when exposed to CP (10-30 min). It also inhibited bean germination during the longest treatment exposure (20-30 min). Regarding germination, only when CP was applied during the shortest period of time $(5 \mathrm{~min})$ had a positive effect (improved its speed: hypocotyl \& radicle length increased), when compared to Control. Some morphological alterations were registered by SM, either on testae (wrinkling) and cotyledons (color changes). Indeed, through SEM, both testae and cotyledon structures showed the disrupting effects on their cell membranes during the treatment more power. The CP treatment, under the current conditions applied, showed effective for fungi inactivation, although it affected some kernel micro-structures and germination. Therefore, further studies will be carried out regarding adjustments on CP conditions, to improve treated beans quality.

Keywords: Non-thermal; Cold plasm; Bean; Fungus; Decontamination

\section{INTRODUCTION}

Beans (Phaseolus vulgaris L.) are one of the most consumed pulses worldwide (Yang et al., 2018). Brazil is the third largest producer, after India and Myanmar. It represents a significant aspect for the country economy, especially for small farmers (Blair et al., 2013).

However, when it is stored in inadequate conditions (high moisture and temperature), beans can suffer pests attack, causing qualitative and quantitative losses (Kumar and Kalita, 2017). Fungi infection is the main cause of stored grain damages worldwide after insects infestation (Verga and Teren, 2005). Fungi are indicators of grains quality (deterioration) and safety (mycotoxins producers), thus responsible for causing serious damages to human and animals health (Katsurayama and Taniwaki, 2017). Among the toxins producers, the Aspergillus and Penicillium genera are the most important in the storage and need to be controlled (Scussel et al., 2018).

The traditional fungal control methods applied during storage (fungicides applications) and in the food industry (thermal treatments) can leave toxic compounds residues and/or induce texture alterations (Niemira, 2012; Misra et al., 2011; Freitas et al., 2017). Therefore, methods that are not aggressive for grains and effective on spores' inactivation are required (Savi et al., 2014). The CP is an example of a new technology. This non-thermal method is reported as a partially or totally ionized gas. It is composed of a subatomic and molecular elements mixture with electromagnetic radiation (UV photons and visible light) able to generate species such as the reactive oxygen (ROS), nitrogen (RNS) and halogen (RHS) (Bourke et al., 2017).

\footnotetext{
*Corresponding author:

Cristina Link Rüntzel, Mycotoxicology and Food Contaminants laboratory- LABMICO, Food Science and Technology department, Agricultural Sciences Center, Santa Catarina Federal University. E-mail: link.cristina12@gmail.com
}

Received: 04 July 2019; $\quad$ Accepted: 11 October 2019 
The CP antifungal power occurs due to its effect on the cells membrane surface (wall) and in the inner components, causing dehydration through UV light and DNA chains breakdown, making difficult to replicate (Afshari and Hosseini, 2014; Devi et al., 2017). It's important to highlight that, among the gases that can be utilized in this process; the most common for microbiological decontaminations is the oxygen, it forms ozone, an important known oxidizer. One of the $\mathrm{CP}$ advantages in food, refer to minimizing effects, different from those caused by the high temperatures procedures. Besides, it decreases the use of chemical fungicides, thus meeting the consumer demand for safe foods (Niemira, 2012; Misra et al., 2011).

Regarding food CP application, several studies reported its effect against microorganisms (bacteria: Bacillus spp., Escherichia coli, Salmonella spp., Staphylococcus aureus - and fungi: Aspergillus flavus, A. parasiticus, Penicillium spp.) (Selcuk et al., 2008; Han et al., 2016; Thomas-Popo et al., 2019; Hou et al.; 2019). The investigations were carried out for different fruits, grains and pulses (Misra et al., 2011; Mitra et al., 2013; Dasan et al., 2016; Devi et al., 2017; Ukuku et al., 2019). It has also been studied for products such as, cereal bars and biodegradable films (starch-based/zein-with chitosan) (Chen et al., 2019; Nieves et al., 2019). However, for fungi decontamination in beans, CP detailed effects have still been unexplored.

Regarding changes in the food tissue caused fur $\mathrm{CP}$ and registered in microscopy, especially for scanning electron microscopy (SEM), some studies were performed in products such as apple and corn and peanuts (Dasan et al., 2016; Devi et al., 2017; Ukuku et al., 2019).

The objective of current study was to investigate the effectiveness of cold plasma on the inactivation of fungi present naturally in kernels beans, including its possible alterations on quality characteristics (inner and outer microstructures) and germination capacity.

\section{MATERIAL AND METHODS}

\section{Material}

(a) Sample: beans, cultivar SCS204, Class: black $(1 \mathrm{Kg})$, naturally contaminated, kindly provided by the Santa Catarina Integrated Company of Agricultural Development-CIDASC (moisture content - mc, water activity $-a_{w}$, and total fungi load - TFL of $17.5 \%$, 0.6037 and $1,7 \times 10^{3} \mathrm{CFU} / \mathrm{g}$, respectively).

(b) Culture medium and chemicals: potato dextrose agar (PDA), Kasvi (Pinhais, PR, Brazil), chloramphenicol, Vetec (Rio de Janeiro, RJ, Brazil) and methylene blue dye, Exôdo Científica (São Paulo, SP, Brazil). (c) Equipment: CP system - reactor Tip Plane Type (glass chamber - $110.5 \times 105.0 \mathrm{~mm}$, with silicone cap and oxygen gas input) with dieletric barrier discharge (10 $\mathrm{mm}$ distance between the electrodes) and a VARIAC utilized as controller (input: $510 \mathrm{~W}$ ) and a power supply $(17 \mathrm{kv})$. Microbiological oven, Quimis (Diadema, SP, Brazil); microwave oven, Philco (São Paulo, SP, Brazil); autoclave, Phoenix (Araraquara, SP, Brazil); laminar flow cabinet, Veco (Campinas, SP, Brazil) and caliper, Santa Clara (São Paulo, SP, Brazil) Microscopes - (c.1) light -LM (100x), Olympus (São Paulo, SP, Brazil), (c.2) stereo- SM (180x), Opticam (Tokyo, Kt., Japan) and (c.3) scanning electron- SEM(5000x), model JSM6390LV, Jeol (Peabody, Mass., USA); gold coating machine, model EMScd500, Leica (Leider, Ill., USA).

(d) Other materials: mini-Petri dishes $(60 \mathrm{~mm}$ Æ), Kasvi (Santa Catarina, Brazil).

\section{Method}

(a) Beans preparation prior CP treatment: beans kernels were arranged $(n=3)$ on previously prepared Petri dishes with PDA - only one grain/dish. They were divided into two main groups: Control (CG - not CP treated) and Treated (TG - CP treated) for exposure times of 5, 10, 20 and $30 \mathrm{~min}$. Total fungi load (TFL) was carried out prior the kernels treatment by applying the method prescribed by Samson, et al. (2006).

(b) CP treatment: the TG plates were placed into the reactor then applied $8 \mathrm{kV}$ intensity $(510 \mathrm{~W})$ and exposed during different lengh of times (5 to $30 \mathrm{~min}$ ).

(c) Post-treatment $\mathrm{CP}$ effect analysis: the effect on fungal growth inhibition, germination capacity and microstructures alterations were carried out through the following analyses. (c.1) mycology tests - the CP treatment on fungi spores was evaluated through plates incubation for 7 days, at $25^{\circ} \mathrm{C}$ (Berjak, 1984). The antifungal effect was then monitored through colony growth. The colonies that were able to grow, were identified through the microculture technique (Weber e Pitt, 2000; Samson et al., 2006). (c.2) germination capacity -each kernel (TG and CG) germination capacity was evaluated by monitoring their embryo tissues behavior through the development of the radicle (primary root) and hypocotyl (embryonic stem) during the incubation time (Day 1 to 7 at $25^{\circ} \mathrm{C}$ ). Micrographs were taken from SM and SEM observation. (c.3) micro-structures characteristics- (c.3.1) beans parts and sections preparation - each bean kernel was prepared as follows, for SM- sectioned in two parts corresponding to the cotyledons and for SEM - different parts sectioned in cubes (testae/hilum/cotyledon/ epicotyls/primary root) and bean cross sectioned. The stub preparation followed the specific protocol. 


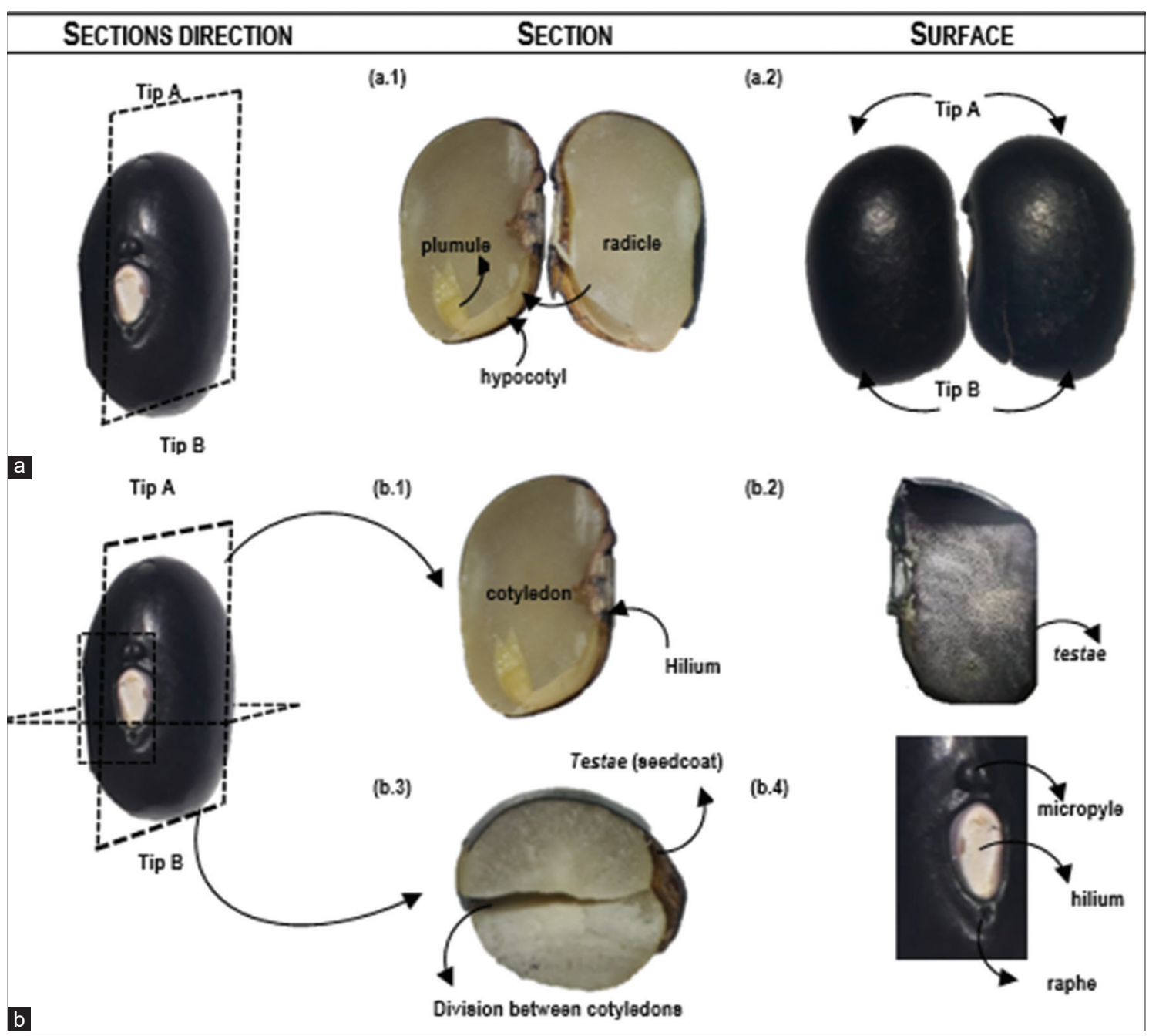

Fig 1. Bean (Phaseolus Vulgaris L.) kernels sections preparation for microscopy visualization by: (a) stereo (SM) (a.1) cotyledons, (a.2) testae and (b) scanning electron (SEM) (b.1) cotyledon (length wise - inner) and (b.2) testae (inner and outer surfaces); (b.3) whole kernel (cross sectioned) and (b.4) hilum surface.

Posteriorly, kernels were gold coated ( $40 \mathrm{~nm}$ layer) under vacuum in a planetary base and taken to the microscopes (Scussel et al., 2014). (c.3.2) microscopy observationsby SM- the structural characteristics of different bean parts and their morphology were registered through micrographs (taken at different amplifications:67-80x) with any tissue variations (TG) compared to CG. For a more precise analysis of the $\mathrm{CP}$ effects changes on the constituents of external and internal structures of the kernels, their tissues were evaluated by SEM - testae/ hilum, cotyledons, starch and germination tissues modifications were observed, then registered through micrographs (taken at different amplifications:1001000x) and their alterations compared to CG (Fig. 1).

\section{RESULTS AND DISCUSSION}

Data obtained on the beans Class black, CP treated (conditions: 8Kv/5-30 min, Tip Plane type) for antifungal inactivation and micro-structures stability showed some variations regarding the conditions applied. Figs. 2-6 show the fungi genera contamination, SM and SEM microscopy characteristics, respectively.

\section{Antifungal CP effects}

Beans naturally contaminated - prior CP treatment

(a) Total fungi load- the bean samples utilized for the CP treatment presented a previous natural contamination of $1.1 \times 103 \mathrm{CFU} / \mathrm{g}$, as expected. Indeed, kernels had a rather high mc $(17.5 \%)$ to allow fungi spores development. That $\mathrm{mc}$ is known as an adequate condition (together with temperature) for fungi development, especially the storage ones (Scussel et al., 2018).

(b) Fungi genera isolated- the fungi colonies isolated (Section 3.1.a) from the bean samples were identified as Aspergillus sp. and Penicillium sp., storage genera which need less mc/aw to proliferate (Fig. 2). Beans samples humidity were of $17.5 \%$ and 0.6037 for mc and aw, respectively. The Aspergillus was the mainly 


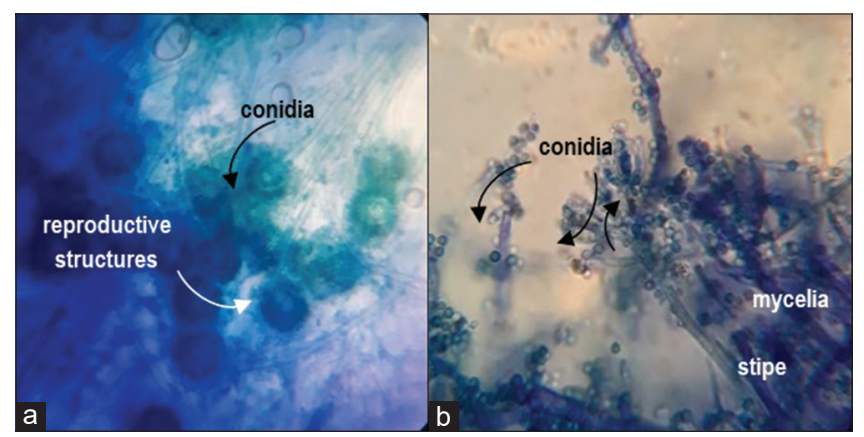

Fig 2. Fungi genera isolated from naturally contaminated bean (Phaseolus vulgaris L.) kernels, Class black: (a) Aspergillus and (b) Penicillium by light microscopy [40X].

genera isolated, with the highest number of colonies growth, compared the other genera. Attention should be payed, regarding these microorganisms, due to their possibility to produce toxins. Aspergillus species can produce mainly the aflatoxins (B1, B2, G1, G2) and ocratoxin A. On the other hand, Penicillium can produce citrinine, cyclipiazonic acid, among others (Scussel et al., 2018). Consequently, their presence can compromise the human and/or animal health, regarding thee toxic characteristics, such as hepatotoxic, nephrotoxic, immunosuppressive, mutagenic and/or carcinogenic (Medeiros et al.; 2012; Prado, 2014; Zhu et al., 2018).

Beans naturally contaminated - post CP treatment

(a) Anti-fungi CP effect and susceptibilities - treatment, under the CP Type (Tip Plane) and conditions $(8 \mathrm{Kv} / 5-30 \mathrm{~min})$ applied showed to be effective on fungal inactivation (100\% reduction - no growth) throughout all the exposure times (10-30 min), except for the shortest. That positive effect, was due to fungi cell walls being affected by the CP components (UV photons, charged particles, radicals, reactive species and ozone) (Afshari e Hosseini, 2014, Bourke et al., 2015). The reactive species of plasma are associated to oxidative effects in external surface of microbial cells. The lipids are the main components affected by the reactive species, as they are distributed (together with proteins) in the membrane surface and are easily hit for plasma. The protein are affected too, through denaturation and cell leak (Misra et al., 2011; Afshari et al., 2014). Regarding the shortest CP exposure (5 min), fungi spores took around three days to start hatch, they were still able to grow (develop into colonies) from Day $4^{\text {th }}$ (both: Aspergillus \& Penicillium), then kept on growing up to Day $7^{\text {th }}$ (countless). That probably occurred due to spores resistance to the short CP oxygen ionized gas exposure (not enough to membrane disintegration). That finding was corroborated by Han et al. (2016) and Lauroussi (2009). Authors reported short contact time between the reactive gas species and the fungi contaminant, promoting a less effective inactivation. Studies also related a better efficacy with longer exposure times (Suhem et al., 2013; Selcuk et al., 2008). Thus corroborating with the registered in the current study (100\% inactivation - longer time -10 to $30 \mathrm{~min}$ ). Selcuk et al. (2008) also reported satisfactory results on fungi decontamination of cereals and pulses naturally contaminated with $A$. parasiticus and Penicillium $\mathrm{sp}$, regarding exposure time variation.

(b) CP treatment variables versus effectiveness - several studies demonstrated a partial or total microorganism load reduction by CP. However, they were carried out by utilizing different conditions, either $\mathrm{CP}$ reactor geometries, the application parameters, level of fungi spores load and/or different species (Grzegorzewski et al., 2011; Suhem et al., 2013; Chaiwat et al., 2016). Other factor, responsible for fungal inactivation efficiency is the CP form of application onto a surface: directly, semi-directly or indirectly. The direct (used in this work) CP application in certain area provides a higher range of reactive species interaction with the microorganism than indirectly (Hertwig et al., 2015).

(c) $\mathrm{CP}$ applications versus pulses: as far as fungi reduction by $\mathrm{CP}$ on pulses, some studies were carried out for beans, chickpeas, lentil, peanuts and soya. Despite that, they were reported CP application at different conditions, such as: Atmospheric Low Pressure, Gas Barrier Discharge, Bell-Jar-Type and Surface MicroDischarge (Selcuk et al., 2008; Mitra et al., 2013; Devi et al., 2017). In the current work, the CP utilized was Tip Plane type, applied directly on the bean surface, keeping a gap (distance between plasma and substrate) of $10 \mathrm{~mm}$, so the reactive species directly affected the sample, contributing to the fungi decontamination efficacy. Thomas-Popo (2019) by using CP with an argonium Gas Barrier Discharge, kept a $20 \mathrm{~mm}$ gap on wheat grains and was able to inactivate the natural microflora, including Escherichia coli and Salmonella enterica. Los et al. (2018) investigated the effect of Gas Barrier Discharge CP on wheat and barley to control potential of native and pathogenic microflora as well of fungi and reported reduction by direct treatment for $20 \mathrm{~min}$. Those findings corroborate to the antifungal potential of the current study, although, by utilizing a different geometry (Tip Plane Type).

\section{Bean kernels micro-structures CP stability - quality related}

As far the susceptibility of the beans tissues microstructures characteristics to $\mathrm{CP}$ application are concerned, by applying both SM \& SEM microscopies, alterations were able to be registered. They were mainly on beans testae and cotyledons. Fig. 4 and 5/6 show the SM and SEM tissues alterations, respectively. 


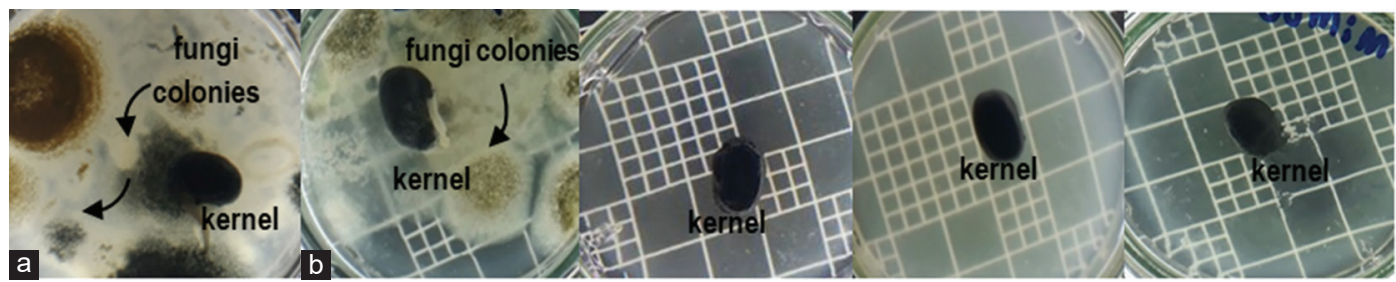

Fig 3. Fungi colonies on bean (Phaseolus vulgaris L.) kernels Class black:(a) Control (not CP treated) and (b) Treated (TG: at 5 , 10, 20 and $30 \mathrm{~min})$ - Day $7^{\text {th }}$.

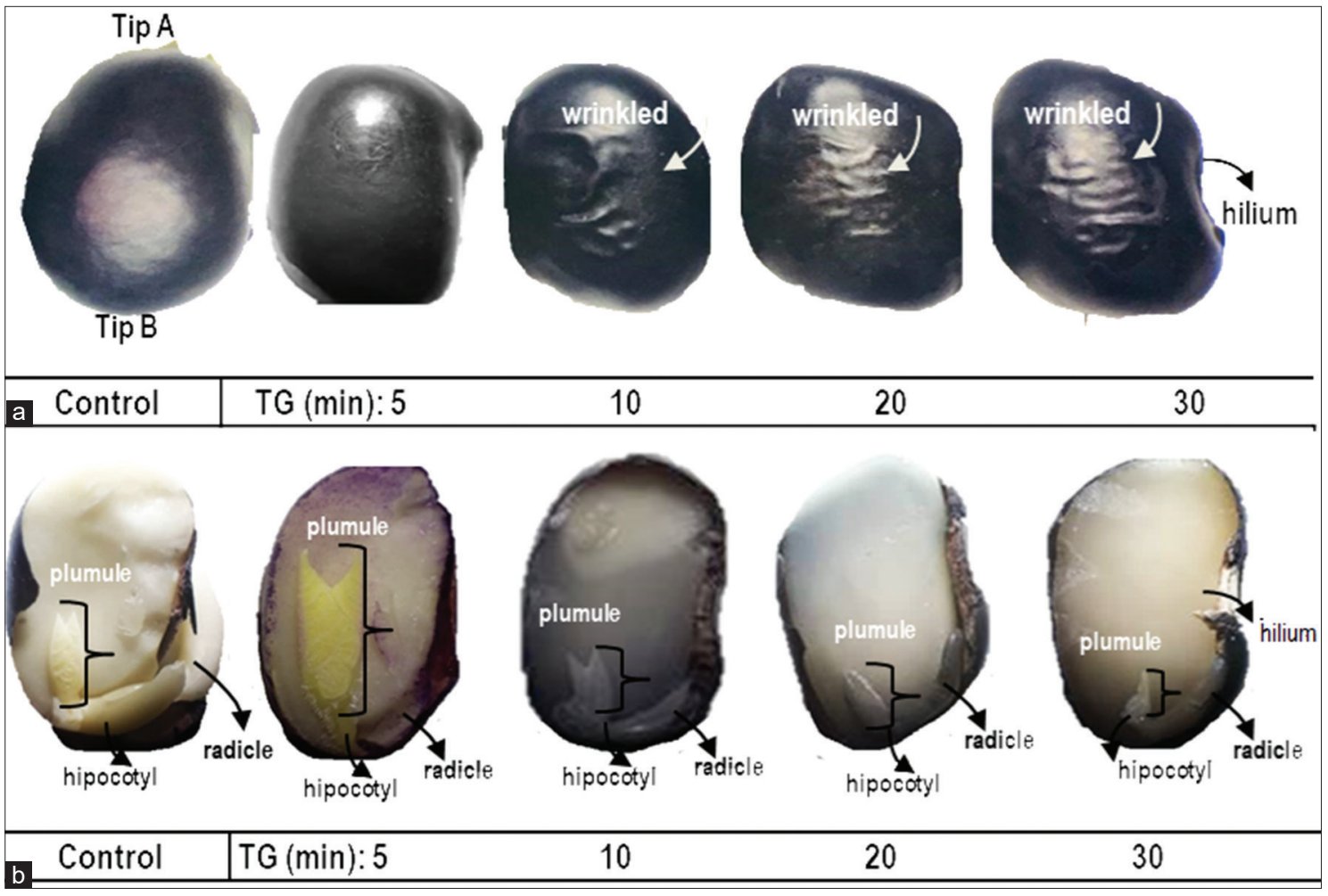

Fig 4. Bean (Phaseolus vulgaris L.) kernels Class black, - testae \& cotyledons surfaces micro-structures characteristics: (a) testae (external) and (b) cotyledons (inner). Control (not treated) and Treated (Cold Plasma: 8 Kv, 5,10, 20 and 30 min exposure time) [SM- 80X] TG: treated group.

SM of bean micro-structures CP treated- the morphohistological characteristics alterations in beans kernel CP treated were registered on the testae and cotyledon tissues as follows.

(a) testae (outer surface)- some changes on the bean external part could be visualized (Fig. 3). Testae developed a wrinkled texture in comparison to the CG (smooth). Dhayal et al. (2006) also observed considerable alterations on the testae caused by $\mathrm{CP}$ (low-pressure) in safflower seeds;

(b) cotyledons (inner surface)-the treatment affected somewhat the bean. It presented color alteration (Fig. 4). Similar changes were also reported by Mitra et al. in chickpea. Authors registered significant alterations related to roughness development when exposed to CP (micro-discharge surface type) during $5 \mathrm{~min}$ (treatment longer of the study) (Mitra et al., 2014). On the other hand, in blueberries (high moisture- fruits) it was noticed color and firmness reduction when submitted to CP (tip: jet) (Lacombe et al., 2015). The food characteristics changes after $\mathrm{CP}$ exposure can be explained by the reactive species action on tissues causing expansion apart from the breaking down of cell membranes (Pasquali et al., 2016). The cotyledon color change, for example, can be explained by a possible beans water exudate when submitted to CP (Bormashenko et al., 2015). Changes in nutritional, sensory and other attributes linked to quality also were registered by Pasquali et al. (2016) for red chicory.

(c) germination: besides the structural characteristics of the bean, another aspect directly related with the application of CP is the germination. In this case, the kernels groups exposed only during 5 and $10 \mathrm{~min}$ germinated (both hypocotyl and radicle were formed). The other groups (exposed to 20 and $30 \mathrm{~min}$ ) did not develop of the radicle (inhibited germination). During 


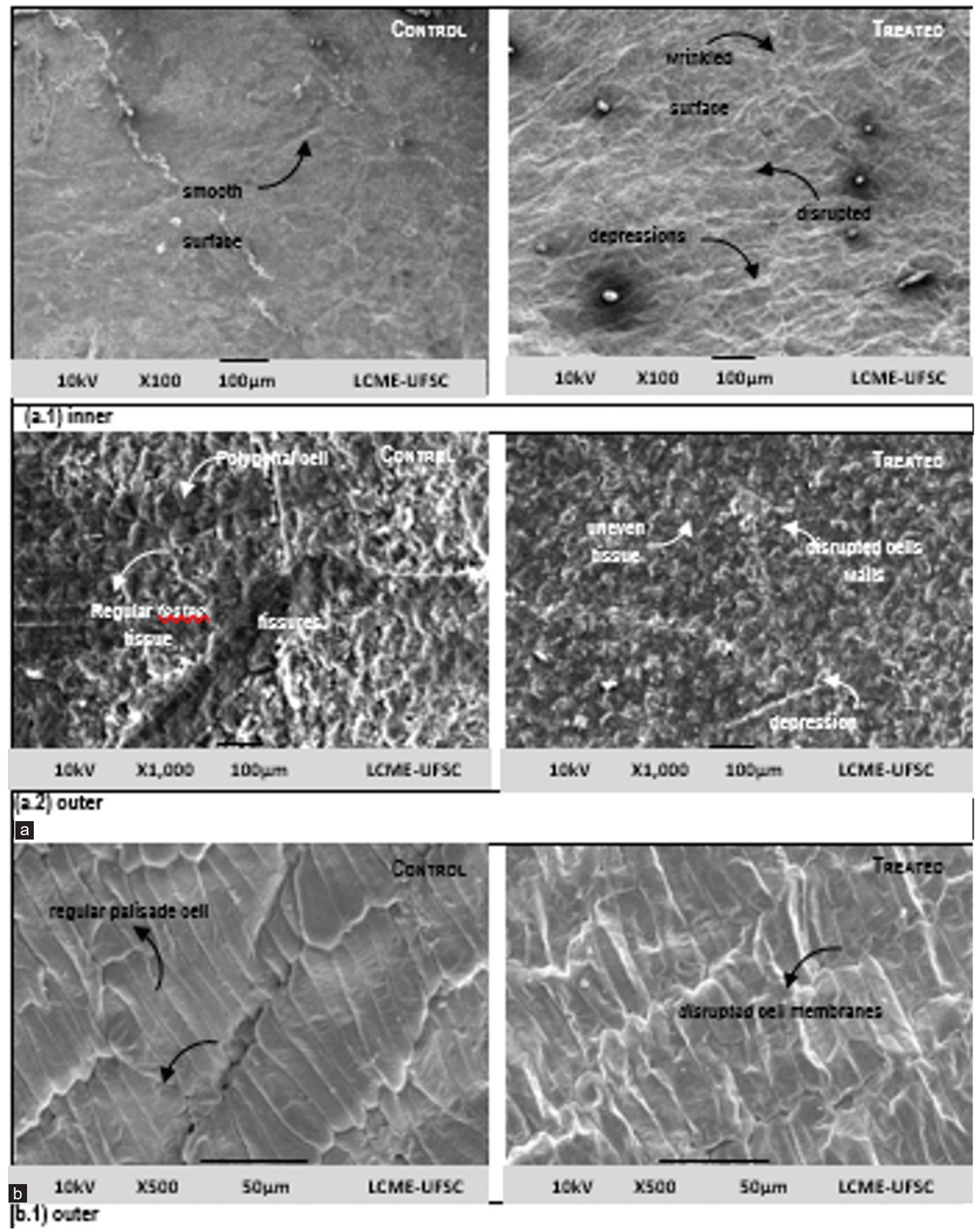

Fig 5. Bean (Phaseolus vulgaris L.) kernel, Class black Scanning electron microscopy of (a) TESTAE and (b) COTYLEDONS surfaces: Control and Treated (exposed to Cold Plasma - Tip Plane: 8 Kv, 30 min exposure time) [100-1000X].

the 5 min exposure (Fig. 4) the structures that give rise to stems and leaves showed size increase (to $16 \mathrm{~mm}$ or 33\% length), than the Control kernel (12 mm). It demonstrated that $\mathrm{CP}$ has a positive effect under the shorter time tested ( $5 \mathrm{~min} / 8 \mathrm{kv}$ ). On the other hand, the growth of the radicle under the 10 min exposure was visually inferior when compared to the CG $(8 \mathrm{~mm})$. Several authors verified that CP stimulated the 

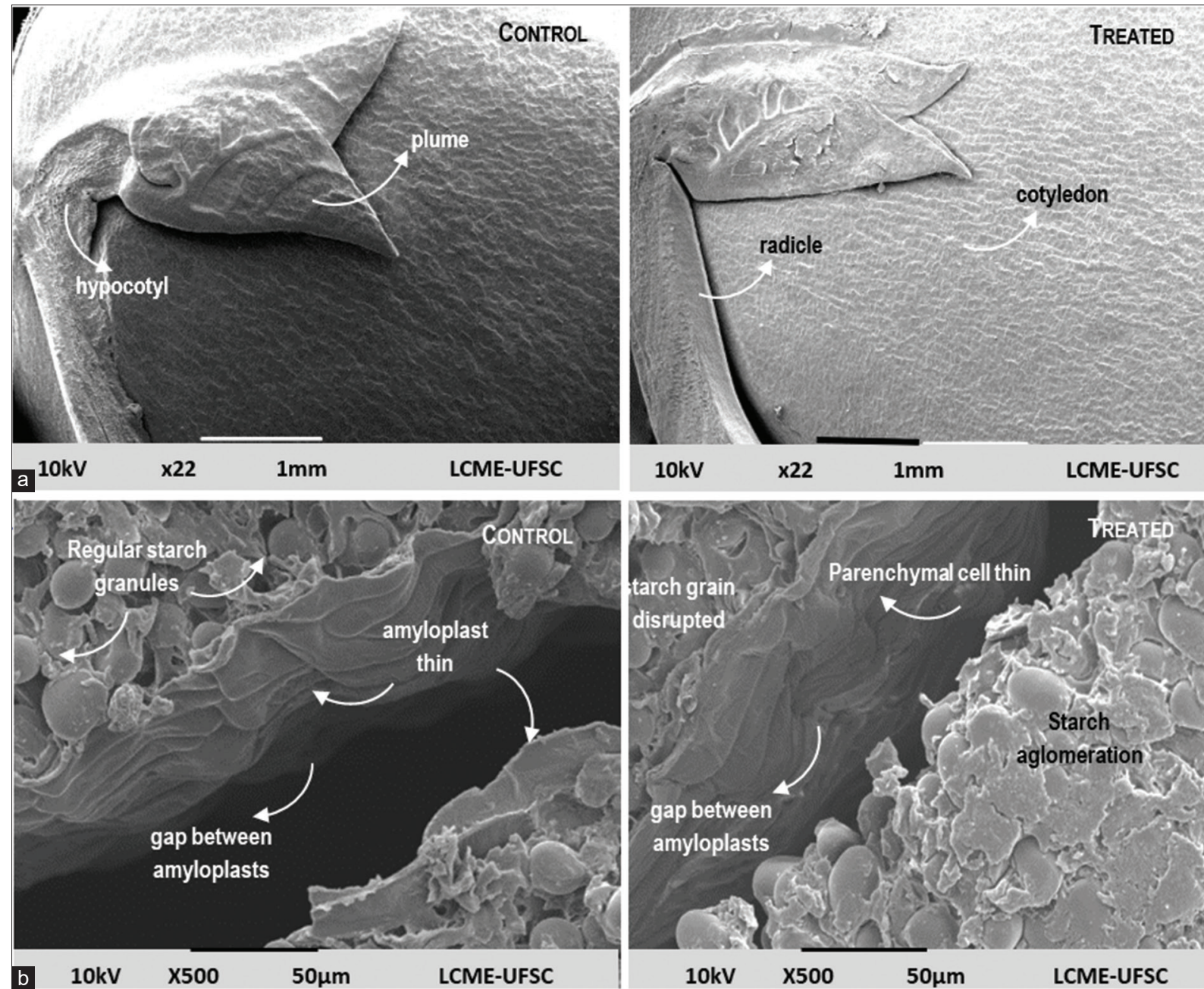

10kV $\quad$ x22 $\quad 1 \mathrm{~mm} \quad$ LCME-UFSC
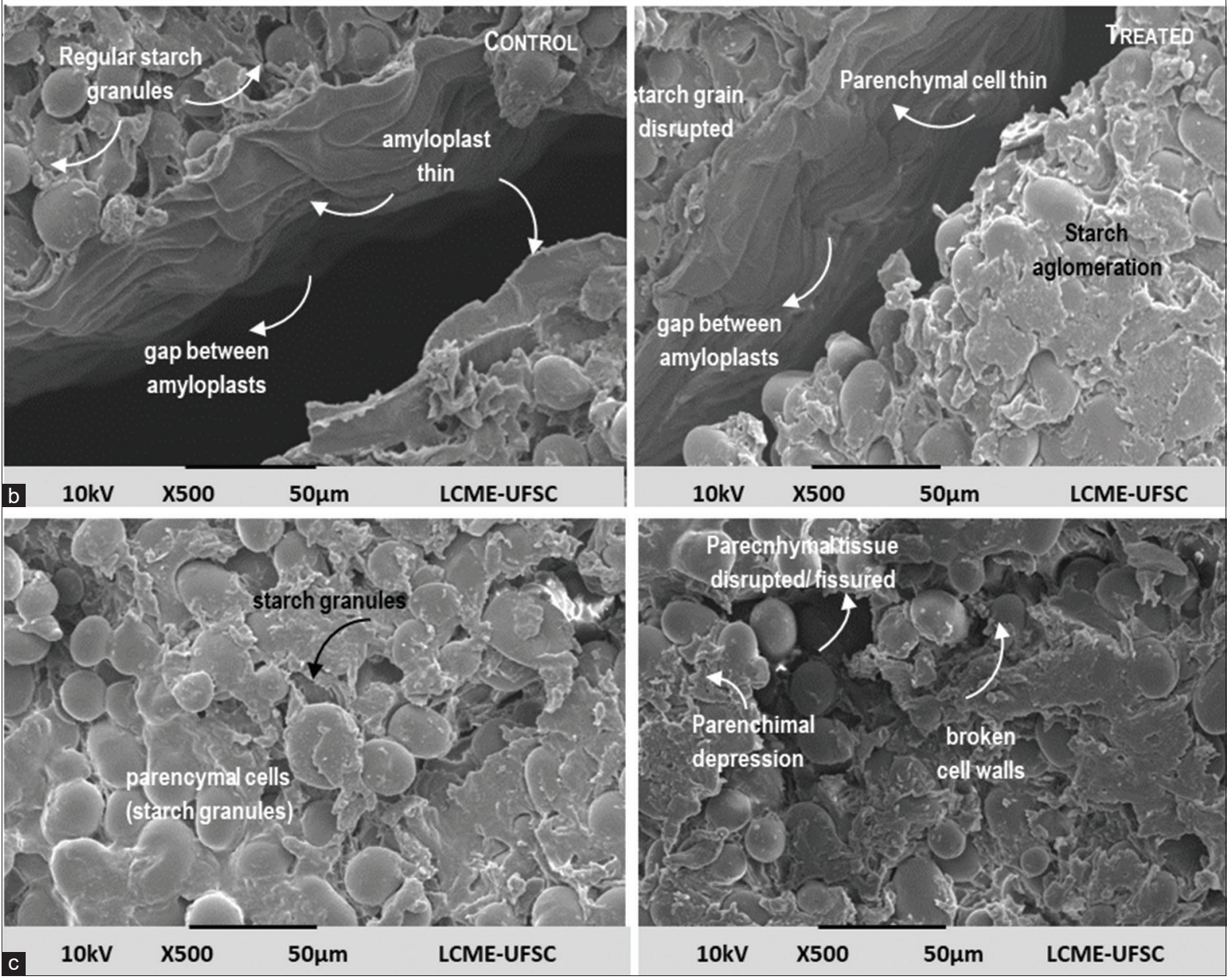

Fig 6. Bean (Phaseolus vulgaris L.) kernel, Class black scanning electron microscopy of cotyledon - starch/parenchymal cells in cross section: (a) germination structures, (b) membrane between amyloplasts and (c) starch morphology and alterations. Control and Treated (exposed to Cold Plasma -Tip Plane Cold Plasma: $8 \mathrm{Kv}, 30$ min exposure time) [500X].

germination process, as Ling et al. (2014) in soybean seeds (15 sec exposure to CP) and Mitra et al. (2014) in the chickpea. (0.5 to 5 min exposure to $\mathrm{CP}$ ). In the current work bean kernels possibly did not germinate due to the damaged structures by long exposure time (germination responsible).
SEM of bean micro-structures CP treated - regarding beans treated micro-structures characteristics and observed by SEM, some subtle differences were noticed as follows (a) testae - control sample showed smoother surface in relation to treated kernel by CP (disrupted cells walls). This alteration can be observed in Fig. 5. 
(b) cotyledon- it also suffered some endosperm microstructures alterations, when compared to Control (Fig. 5). Those kernels CP treated showed palisade broken (disrupted) cells which were mainly on their surfaces (membrane/wall), thus affecting the whole membrane integrity. Different to those of the CG group, that presented uniform and united regular palisade cells, with even membranes. Differences detected in the kernels before and after CP exposure analyzed by SEM was registered also by Grzegorzewski et al. (2011) on lettuce leaves using CP (Atmospheric Pressure). The author noticed erosions and ruptures in the epidermal tissue. In the research carried out by Thirundas et al. (2016) after exposure to CP (for 5 and $10 \mathrm{~min}, 30$ and $40 \mathrm{~W}$ ), SEM revealed cracks and depressions on the basmati rice surface. Ukuku et al. (2019) noticed changes in apples treated with a combination of antimicrobial and CP. Authors reported $\mathrm{CP}$ changed on the apple surface structures but not on bacterial cell structure.

(c) germination: from the SEM micrographs, it was possible to observed that the structures responsible for the germination process, despite whether able to germinate or not, no CP tissues alteration were observed up to the SEM amplification applied [20 to $1000 \mathrm{X}$ ] (Fig. 6). Therefore, the outer structures of plumule, radicle and hypocotyl were not CP affected (they remained intact). Probably to the fact that the Tip Plane CP did not reach strongly to the peripheric region of the kernels. However, as discussed at Section 3.2.c, the CP altered somewhat the germination capacity regarding the radicle length but no SEM micro-structures modifications were observed.

(d) starch: no differences in the granular morphology of cotyledons starch texture were observed in the amyloplasts such as cracks and uneven surface when compared to control (Fig. 6). Although not observed differences on the morphology of the starch granule, some authors confer the effect of CP the formation of cracks and cavities in the starch (Thirumdas et al., 2016). Studies indicated that different $\mathrm{CP}$ reactors are able of altering the carbohydrate chemical composition (Chaiwat et al., 2016), the texture, cooking time and changes in the molecule structure (Thirumdas et al., 2016). This change on starches granules can be useful in the beans, for some characteristics when modified may have interesting consequences for the industry.

SEM is a technique that allows observing with details a material superficie, as foods. Besides structure alteration in beans kernels treated with $\mathrm{CP}$, using this technique in this study, others aspects were registered, as absence of fungi spores in samples. Hereby SEM was a tool very important in the current work.

\section{CONCLUSION}

The CP conditions applied ( $8 \mathrm{kv}$ intensity, 510W power and time 5-30 $\mathrm{min}$ ) showed potential to reduce the total fungal of the naturally contaminated beans exposed to the long time (20/30 min). Despite that, it affected some bean characteristics - cotyledons color and testae wrinkling (10-30 min), observed by SM and SEM. Regarding the CP application for beans during storage, germination inhibition in the time of 10-30 min can be an advantage, because it is not desirable (mainly on top of the silos). Other CP advantage is the to avoid of chemical fungicides application. The inactivation efficiency is dependent of several factors (the plasma generation source utilized, the parameters applied, samples type and microorganism physiological state) - therefore it is very important to take into account those factors when comparing $\mathrm{CP}$ application for different foods and/or literature studies. Further studies on CP effect on beans need to be carried out and also conditions adjusted to reduce sensory alterations.

\section{ACKNOWLEDGEMENTS}

The authors are grateful for the financial support of Coordination of Improvement of Higher Level Personnel (CAPES) and National Council for Scientific and Technological Development (CNPQ) through the granting of research grants, the Federal University of Santa Catarina (UFSC) and the Laboratory of Mycotoxins and Contaminants for Food (LABMICO) for ceding their facilities for the development of this work and for Integrated Company of Agricultural Development of Santa Catarina (CIDASC) by the donation of the grains.

\section{Authors' contributions}

The authors Elisa Siegel Moecke and Vildes Maria Scussel correspondig the advisors this study (correction of work). The others one (Cristina Link Rüntzel, Juliana Regina da Silva, Bruna Aparecida da Silva) colobarrate doing the analyses, analyzing the data and writing the paper.

\section{REFERENCES}

Afshari, R. and H. Hosseini. 2014. Non-thermal plasma as a new food reservation method, its presentand future prospect. J. Paramed. Sci. 5: 116-120.

Berjak, P. 1984. Report of seed storage committee working group on the effects of storage fungi on seed viability: 1980-1983. Seed Sci. Technol. 12: 233-253. 
Blair, M.W., R. V. P. Brondani, L. M. Días and M. J. D. Peloso. 2013. Diversity and population structure of common bean from Brazil. Crop Sci. 53: 1983-1993.

Bormashenko, E., Y. Shapira, R. Grynyov, G. Whyman, Y. Bormashenko and E. Drori. 2015. Interaction of cold radiofrequency plasma with seeds of beans (Phaseolus vulgaris). J. Exp. Bot. 66: 40134021.

Bourke, P., D. Ziuzina, D. Boehm, P. J. Cullen and K. Keener. 2015. The potential of cold plasma for safe and sustainable food production. Trends Biotechnol. 36: 615-626.

Chaiwat, W., R. Wongsagonsup, N. Tangpanichyanon, T. Jariyaporn, P. Deeyai, M. Suphantharika, A. Fuongfuchat, M. Nisoa and S. Dangtip. 2016. Argon plasma treatment of tapioca starch using a semi-continuous downer reactor. Food Bioprocess Technol. 9: 1125-1134.

Chen, G., S. Dong, S. Zhao, S. Li and Y. Chen. 2019. Improving functional properties of zein film via compositing with chitosan and cold plasma treatment. Ind. Crops Prod. 129: 318-326.

Dasan, B. G., I. H. Boyaci and M. Mutlu. 2016. Inactivation of aflatoxigenic fungi (Aspergillus spp.) on granular food model, maize, in an atmospheric pressure fluidized bed plasma system. Food Control. 70: 1-8.

Devi, Y., R. Thirumdas, C. Sarangapani, R. R. Deshmukh and U. S. Annapure. 2017. Influence of cold plasma on fungal growth and aflatoxins production on ground nuts. Food Control. 77: 187191.

Dhayal, M., S. Y. Lee and S. U. Park. 2006. Using low-pressure plasma for Carthamus tinctorium L. Seed surface modification. Vacuum. 80: 499-506.

Freitas, R. S., L. R. A. Faroni, M. E. L. Queiroz, F. F. Heleno and L. H. F. Prates. 2017. Degradation kinetics of pirimiphos-methyl residues in maize grains exposed to ozone gas. J. Stored Prod. Res. 74: 1-5.

Grzegorzewski, A. F., J. Ehlbeck, O. Schlüter, L. W. Kroh and S. Rohn. 2011. Treating lamb's lettuce with a cold plasma e Influence of atmospheric pressure ar plasma immanent species on the phenolic profile of Valerianella locusta. LWT Food Sci. Technol. 44: 2285-2289.

Han, L., S. Patil, D. Boehm, V. Milosavljević, P. Cullen and P. Bourke. 2016. Mechanisms of inactivation by high-voltage atmospheric cold plasma differ for Escherichia coli and Staphylococcus aureus. Appl. Environ. Microbiol. 82: 450-458.

Hertwig, C., K. Reineke, J. Ehlbeck, D. Knorr and O. Schlüter. 2015. Decontamination of whole black pepper using different cold atmospheric pressure plasma applications. Food Control. 55: 221-229.

Hou, Y., R. Wang, Z. Gan, T. Shao, X. Zhang, M. He and S. Sun. 2019. Effect of cold plasma on blueberry juic quality. Food Chem. 290: 79-86.

Katsurayama, A.M. and M. Taniwaki. 2017. Fungos e aflatoxinas no arroz: Ocorrência e significado na saúde do consumidor. Braz. J. Food Technol. 20: 01-13.

Kumar, D. and P. Kalita. 2017. Reducing postharvest losses during storage of grain crops to string then food security in developing countries. Foods. 6: 8.

Lacombe, A., B. A. Niemira, J. B. Gurtler, X. Fan, J. Sites, G. Boyd and $\mathrm{H}$. Chen. 2015. Atmospheric cold plasma inactivation of aerobic microorganisms on blueberries and effects on quality attributes. Food Microbiol. 46: 479-484.

Laroussi, M. 2009. Low temperature plasmas for medicine? IEEE Trans. Plasma Sci. 37: 714-725.

Ling, L., J. Jiafeng, L. Jiangang, S. Minchong, H. Xin, S. Hanliang and D. Yuanhua. 2014. Effects of cold plasma treatment on seed germination and seedling growth of soybean. Sci. Rep. 4: 1-7.

Los, A., D. Ziuzina, S. Akkermans, D. Boehm, P. J. Cullen, J. Vanimpe and P. Bourke. 2018. Improving microbiological safety and quality characteristics of wheat and barley by high voltage atmospheric cold plasma closed processing. Food Res. 106: 509-521.

Medeiros, F. H. V., S. J. Martins, T. D. Zucchi, I. S. Melo, L. R. Batista and J. C. Machado. 2012. Biological control of mycotoxinproducing molds. Ciên. Agrotecnol. 36: 483-497.

Misra, N.N., Tiwari, B.K., Raghavarao, K.S.M.S., Cullen, P.J. 2011. Non thermal plasma inactivation of food-borne pathogens. Food Eng. Rev. 3: 159-170.

Mitra, A., Y. F. Li, T. G. Klämpfl, T. Shimizu, J. Jeon, G. E. Morfill and J. L. Zimmermann. 2013. Inactivation of surface-borne microorganisms and increased germination of seed specimen by cold atmospheric plasma. Food Bioprocess Technol. 7: 645653.

Niemira, B. A. 2012. Cold plasma decontamination of foods. Ann. Rev. Food Sci. Technol. 3: 125-142.

Nieves, I. S., E. Hernández-Hernández, G. Neira-Velázquez, E. M. Sánchez, G. Mendez-Montealvo and G. Velazquez. 2019. Hexamethyl disiloxane cold plasma treatment and amylose content determine the structural, barrier and mechanical properties of starch-based films. Int. J. Biol. Macromol. 124: 65-658.

Prado, G. 2014. Contaminação de alimentos por micotoxinas no Brasil e no mundo. Rev. Saúde Pública SUS. 2: 13-26.

Pasquali, F., A. C. Tratakos, A. Koidis, A. Berardinelli, C. Cevoli and L. Ragni. 2016. Atmospheric cold plasma process for vegetable leaf decontamination: A feasibility study on radicchio (red chicory, Cichorium intybus L.). Food Control. 60: 552-559.

Samson, R. A., S. B. Hong and J. C. Frisvad. 2006. Old and new concepts of species differentiation in Aspergillus. Med Micol. 44: 133-148.

Savi, G. D., K. C. Piacentini, K. O. Bittencourt and V. M. Scssel. 2014. Ozone treatment efficiency on Fusarium graminearum and deoxynivalenol degradation and its effects on whole wheat grains (Triticuma estivum L.) quality and germination. J. Stored Prod. Res. 59: 245-253.

Scussel, V. M., D. Manfio, G. D. Savi and E. H. S. Moecke. 2014. Stereoscopy and scanning electron microscopy of Brazil nut (Bertholletia excelsa H.B.K.) shell, brown skin, and edible part: Part one-healthy nut. J. Food Sci. 79: 1443-1453.

Scussel, V. M., G. D. Savi and A. M. Kluczkovvki. 2018. Fungos E Micotoxinas Associados Aos grãos armazenados. In: I. Lorini, L. H. Miike, V. M. Scussel and L. R. D. Faroni (Eds.), Armazenagem de Grãos. Instituto BioGeneziz, Jundiaí, SP.

Selcuk, M., L. Oksuz and P. Basaran. 2008. Decontamination of grains and legumes infected with Aspergillus spp. and Penicillum spp. by cold plasma treatment. Bioresour Technol. 99: 5104-5109.

Suhem, K., N. Matan, M. Nisoa and N. Matan. 2013. Inhibition of Aspergillus flavus on agar media and brown rice cereal bars using cold atmospheric plasma treatment. Int. J. Food Microbiol. 161: 107-111.

Thirumdas, R., C. Saragapani, M. Ajinkya, R. Deshmukh and U. Annapure. 2016. Influence of low pressure cold plasma on cooking and textural properties of brown rice. Innov. Food Sci. Emerg. Technol. 37: 53-60.

Thomas-Popo, E., A. Mendonça, N. N. Misra, A. Little, Z. Wan, R. Moutiq, S. Coleman and K. Keener. 2019. Inactivation of Shiga-toxin producing Escherichia coli, Salmonella enterica and 
natural microflora on tempered wheat grains by atmospheric cold plasma. Food Control, 104: 231-239.

Ukuku, D. O., B. A. Niemira and J. Ukanalis. 2019. Nisin-based antimicrobial combination with cold plasma treatment inactivates Listeria monocytogenes on Granny Smith apples. LWT. 104 120-127.

Verga, B. T. and T. Teren. 2005. Mycotoxin producing fungi and mycotoxins in foods in Hungary. J. Acta Aliment. 34: 267-275.
Weber, R. W. S. and D. Pitt. 2000. Teaching techniques for mycology: 11. Riddell's slide cultures. Mycologist. 14: 118-120.

Yang, Q. Q., R. Y. Gan, Y. Y. Ge, D. Zhang and H. Corke. 2018. Polyphenols in common beans (Phaseolus vulgaris L.): Chemistry, analysis, and factors affecting composition. Compr. Rev. Food Sci. Food Safety, 17: 1518-1539.

Zhu, F. 2018. Effect of ozone treatment on the quality of grain products. Food Chem. 264: 358-366 